\title{
An interrogation of the MQH correlation to describe centre and near corner pool fires
}

\author{
M.Akasha Azhakesan, ${ }^{1}$ T.J. Shields, ${ }^{1}$ G.W.H. Silcock ${ }^{1}$ and J.G. Quintiere ${ }^{2}$ \\ ${ }^{1}$ FireSERT, University of Ulster, 75, Belfast Road, Carrickfergus, BT40 3PW, \\ Northern Ireland; ${ }^{2}$ University of Maryland, U.S.A.
}

\begin{abstract}
An experimental study of liquid pool fires was undertaken in the corner and centre fire geometries. An Industrial Methylated Spirits fuel placed in square trays and elevated from the floor was used in the study. The fuel trays ranged in size from a $0.2 \mathrm{~m}$ tray which was used in a $1 / 3$ scale test enclosure to $0.5-1.0 \mathrm{~m}$ trays used in an ISO sized room. Measured, well mixed ceiling gas temperatures and energy release rates were correlated with two dimensionless groups as used in the well known McCaffrey, Quintiere, Harkleroad $(\mathrm{MQH})$ correlation. An initial interrogation of the MQH correlation suggests that the modification to the $\mathrm{MQH}$ correlation suggested by Mowrer and Williamson for the corner fire geometry is satisfactory. In the case of the centre room fires, correlation of the data suggested a proportionality factor $\mathrm{C}_{\mathrm{T}}$ which was at the upper limit of the data correlation shown in the original $\mathrm{MQH}$ work. This result may be attributable to intermittent flames approaching the ceiling for these tests where quality data was only available tests with the doorway at half width and for large fuel trays. The paper addresses key factors that need further investigation for validating and refining the MQH correlation(s).
\end{abstract}

KEYWORDS MQH correlation, Discrete Liquid pool fires, Centre and near Corner fire geometries

\section{NOMENCLATURE}

$\mathrm{A}_{\mathrm{i}} \quad$ Area of the $\mathrm{i}^{\text {th }}$ material bounding the compartment including walls, ceiling, glazing and floor, $\mathrm{m}^{2}$

$\mathrm{A}_{\mathrm{T}} \quad$ Total internal area excluding doorway, $\mathrm{m}^{2}$

$\mathrm{A}_{\mathrm{v}}, \mathrm{H}_{\mathrm{v}} \quad$ Doorway opening area, $\mathrm{m}^{2}$, doorway height, $\mathrm{m}$

$\mathrm{C}_{\mathrm{p}}, \rho_{\mathrm{o}}, \mathrm{T}_{\mathrm{o}} \quad$ Specific heat, $\mathrm{J} / \mathrm{kg} / \mathrm{K}$, ambient density, $\mathrm{kg} / \mathrm{m}^{3}$, ambient temperature, $\mathrm{K}$

$\mathrm{C}_{\mathrm{T}} \quad \mathrm{K}$, slope of curve defined in eqn.2 and is a function of the fuel/wall(s) geometry

$\mathrm{dT}_{\mathrm{p}} \quad$ Temperature rise above ambient in the far field fire plume

$\mathrm{dT} \quad$ Temperature rise above ambient in the well mixed, ceiling gas layer

$\mathrm{h}_{\mathrm{k}} \quad$ Effective heat transfer coefficient, $\mathrm{kW} / \mathrm{m}^{2} / \mathrm{K}$

$\mathrm{k \rho C}_{\mathrm{p}} \quad$ Effective thermal inertia of the bounding surfaces, $\mathrm{J} / \mathrm{m}^{2} / \mathrm{s}^{1 / 2} \mathrm{~K}$

$\mathrm{k}_{\mathrm{s}} \quad$ Thermal conductivity of material, $\mathrm{kW} / \mathrm{m} / \mathrm{K}$

$m_{p} \quad$ Mass entrainment rate into the far field plume region, $\mathrm{kg} / \mathrm{s}$ 
$\mathrm{z}_{\mathrm{n}} \quad$ Height of hot layer above virtual origin of plume, $\mathrm{m}$

$\alpha_{\mathrm{s}} \quad$ Thermal diffusivity of material, $\mathrm{m}^{2} / \mathrm{s}$

N.B. All other symbols are defined in the text

\section{INTRODUCTION}

One of the accepted means of expressing the relative fire hazard in a compartment fire has been to associate a critical threshold hot gas layer temperature, eg., $600^{\circ} \mathrm{C}$ at which discrete event the imminence of room flashover is indicated[1,2]. Thus, McCaffrey et al [1] performed a regression analysis on over 100 experiments of enclosure fires with fire loads placed at the room centre. The regression analysis correlated the upper gas layer temperatures measured in rooms with vertical openings to the heat release rate (HRR),

$Q$ and various room parameters. The principal latter parameters are an effective conduction heat transfer coefficient, $\mathrm{h}_{\mathrm{k}}$, convection and radiation being already implicit in the correlation[1,2], the total bounding surface area excluding vent area, $\mathrm{A}_{\mathrm{T}}$ and the opening factor, $A_{v}\left(H_{v}\right)^{1 / 2}$. In the case of simple geometries and excluding very small compartments, it has been shown that a good estimate of compartment fire hazard with reference to the possibility of room flashover is made with the MQH correlation 1,2] compared to more complex models such as CFAST. This has been given additional utility implied by the generality of the $\mathrm{MQH}$ correlation as suggested by Mowrer and Williamson (heretofore referred to as MW [3]) who have ostensibly extended the correlation to fires at room corners and sidewalls by an extension of plume theory. Their deductions were however tested with a limited number of experiments in a Gypsum Plasterboard (PLA) lined room with a controlled propane gas ignition source $(0.3 \mathrm{~m}$ square and of $0.3 \mathrm{~m}$ height) having a limiting heat output of $160 \mathrm{~kW}$ [3].

Furthermore, the results of studies conducted elsewhere in corner and sidewall geometries have been interpreted in [4] to imply much greater differences in the entrainment of air into the corner and sidewall geometries than suggested in [3]. Recent analysis of studies conducted at FireSERT in well instrumented full scale (modified ISO scale room) and third scale enclosures $[5,6,7]$ provided an opportunity to study the validity and generality of the MQH correlation and the associated MW modifications. The studies encompassed fire spread over combustible linings [5] and of discrete liquid pool fires used in glazing related studies. In the latter studies, the square fuel trays used ranged in size from $0.5 \mathrm{~m}$ to $1.0 \mathrm{~m}$ [6]. This paper presents an initial analysis of the results of the MQH correlation deduced for discrete pool fire sources located in near corner and centre configurations in enclosures lined with non combustible Fiberboard (Duraboard Tm) surfaces with fully opened and half opened vent widths.

\section{EXPERIMENTAL DETAILS}

The experimental facility shown in fig. 1 below has been detailed elsewhere $[5,6,7]$. 


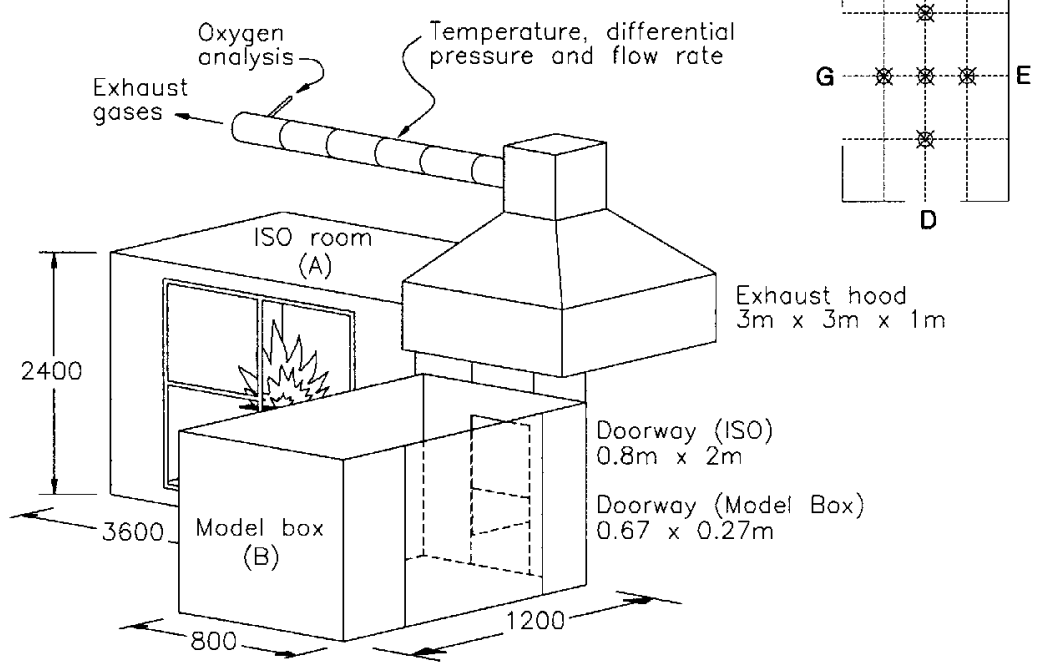

Fig. 1. Schematic of the full and reduced scale test enclosures with ceiling TC layout shown

Both the enclosures shown have been lined internally with low density insulation fibreboard (Duraboard) with an effective $\mathrm{k} \rho \mathrm{c}$ of $0.02 \mathrm{~J} / \mathrm{m}^{2} / \mathrm{s}^{1 / 2} / \mathrm{K}$ at $600^{\circ} \mathrm{C}$. The thicknesses of the Duraboard at the walls and ceiling of the large ISO scaled room were 18 and $22 \mathrm{~mm}$ respectively and that in the $1 / 3$ scale enclosure being $25 \mathrm{~mm}$ all round. The latter was backed by $12 \mathrm{~mm}$ thick fire retarded chipboard (FRC) whilst in the large room, $150 \mathrm{~mm}$ thick concrete blocks were used, which also formed the floor of the enclosure. In the $1 / 3$ scale box, the floor was lined with $12 \mathrm{~mm}$ thick Calcium Silicate board. The west wall, fig.1, was either doubly or singly glazed in the case of the large room and always double glazed in the $1 / 3$ scaled room.

The rooms were instrumented with bidirectional probes at the centre of the door vent (410 in number) and thermocouples were placed at $100 \mathrm{~mm}$ below the ceiling at the 4 quadrants $(25 \mathrm{~mm}$ for the $1 / 3$ scale) including one at the ceiling midpoint. These TC outputs were used as a representative measure of the temperature of the well stirred gas layer at the ceiling as indicated by plots of the averaged ceiling temperature at the four quadrants against the measured mid-ceiling gas temperature illustrated here for the large scale room, fig.2. Other TC's included thermocouple trees placed at the central door vent adjacent to the bidirectional probes and at the front SW corner of the room. The mass loss of the pool fire ignition source, net heat release rate (HRR), surface heat fluxes measured by Gardon Gauges and video observations were also simaltaneously recorded at 5 second intervals. The square pool ignition source was elevated $400 \mathrm{~mm}$ from the floor $(\sim 100 \mathrm{~mm}$ for the $1 / 3$ scale) and placed at $\sim 15 \mathrm{~mm}$ from the room corner for the large 
scale tests and at $\sim 15 \mathrm{~mm}$ in the case of the small scale box. The fuel pan size used in the small scale enclosure was $200 \mathrm{~mm}$ square.

Fig. 2 Corner double glazing test with $0.55 \mathrm{~m}$ corner tray, full doorway width, averaged ceiling gas temperatures at four quadrants $100 \mathrm{~mm}$ below the ceiling vs mid-ceiling gas temperature

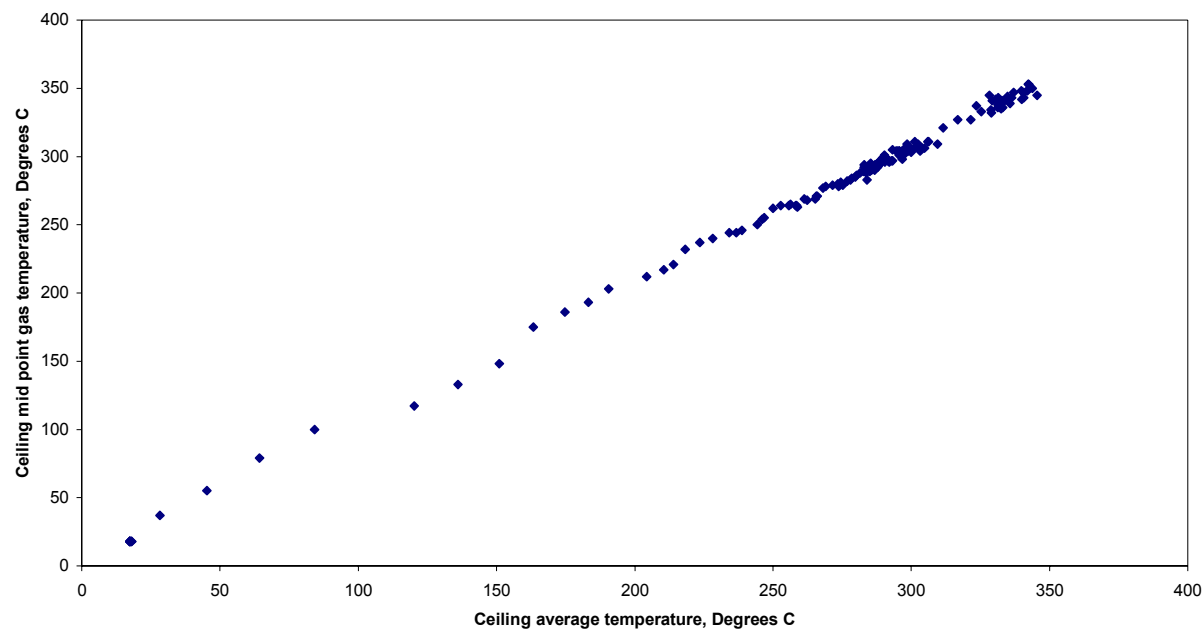

The fuel utilised was a mineralised industrial methylated spirits (IMS) which gave a radiant yellow turbulent diffusion flame with a quasi steady state energy output of about $155+/-35 \mathrm{~kW}$ over $800 \mathrm{~s}$ whereas the smaller fuel package delivered an output of $\sim 14.5+/-4.5 \mathrm{~kW}$. In the following study, the doorway dimensions in the ISO scaled room were $2 \mathrm{~m}$ by $0.8 \mathrm{~m}$ wide and at half width or $0.4 \mathrm{~m}$ for the centre geometry fires and single glazed corner fires. In the case of the two other tests conducted with a $0.55 \mathrm{~m}$ square fuel tray placed $50 \mathrm{~mm}$ from the room corner in the large room with double glazed units in one case and the single test reported for the 1/3 scale model box, the vents were fully open. The net energy release (HRR) was measured by oxygen depletion calorimetry.

\section{THEORETICAL BACKGROUND}

The MQH correlation was derived from an approximate energy balance on what was assumed to be a well stirred upper hot gas layer in order to generate the relevant dimensionless groups. This approach was suggested by the results of plume theory $[1,3,4]$. Here, the properties in the far field region above the flame can be described by the classical theory of point source buoyant plumes [8] as in the far field region, the difference between the distributed turbulent diffusion flame source and a point source becomes negligible. Thus the temperature rise, $\mathrm{dT}_{\mathrm{p}}$ above the idealised point source of energy can be related to the energy release rate of the source, $\dot{Q}$ and the height ' $\mathrm{z}$ ' above the source as,

$$
d T_{p} \propto \dot{Q}^{2 / 3} z^{-5 / 3}
$$


In [1], considerations of the energy balance on the well mixed upper gas layer and doorway mass flow rates followed by linear regression analysis of more than 100 room centre fires data yielded the following power law expression, namely,

$$
d T=C_{T}\left[\frac{\dot{Q}}{\sqrt{g} c_{p} \rho_{o} T_{o} A_{v} \sqrt{H_{v}}}\right]^{2 / 3}\left[\frac{h_{k} A_{T}}{\sqrt{g} c_{p} \rho_{o} A_{v} \sqrt{H_{v}}}\right]^{-1 / 3}
$$

The details are given in refs. [1,3]. In the results section below, figs. 6-7, the first term in brackets is represented as Qo* and the second term in brackets as QL*. For a developing fire in the early stages of fire growth and at an exposure time less than a boundary heat penetration time $\mathrm{t}_{\mathrm{p}}$ defined by $t_{p}=l^{2} / 4 \alpha_{s}$ for a semi-infinite slab of thickness ' $\mathrm{l}$ ', an effective surface heat transfer coefficient, $h_{k}$ can be defined. In the case of composite bounding elements of area, $\mathrm{A}_{\mathrm{i}}$,

$$
h_{k}=\sum_{i}^{n}\left(A_{i} / A_{T}\right)\left(k \rho c_{i} / t\right)^{1 / 2}
$$

Due to the uncertainties associated with the relevant value of $\mathrm{k}_{\mathrm{s}}$ as appearing in the expression $h_{k=} k_{s} / l$, used to approximate $h_{k}$ during the steady state steady state period following $t_{p}$, it was decided in this work to use the value of $h_{k}$ evaluated at $t=t_{p}$ for the latter period. For the case of discrete centre fires, $\mathrm{MQH}$ found that $\mathrm{C}_{\mathrm{T}}=1.63 * \mathrm{~T}_{\mathrm{o}}$ could be described by a mean value of $480 \mathrm{~K}$ (or $473 \mathrm{~K}$ for $\mathrm{T}_{0}=290 \mathrm{~K}$ as utilised in this work). In comparison, Mowrer and Williamson suggested that $\mathrm{C}_{\mathrm{T}}=804 \mathrm{~K}$ and $615 \mathrm{~K}$ for corner and sideweall fire geometries respectively, i.e., $\mathrm{C}_{\mathrm{T}}$ is dependant on the location of the fuel array. This was arrived at by simple considerations of plume theory in conjunction with the Mirror Model [3] applied to fires near wall and corner surfaces.

Thus, starting from the observation that the temperature rise within an unconfined far field plume can be described by, $d T_{p} \propto Q^{n} / m_{p}$, and that the presence of adjacent surfaces could reduce the air entrainment rate, $M \& W$ [3] estimated the entrainment rate reduction factor, EF into the fire plume due to the presence of nearby surfaces and hence the expected increase in the plume temperature rise. Using the Mirror model, the EF for the corner surfaces geometry was deduced to be $0.25^{*} 2^{\mathrm{n}}$ and $0.5^{*} 2^{\mathrm{n}}$ for wall fires respectively. In the far field plume where $n=1 / 3$ the EFs were deduced to be 0.4 and 0.63 for the corner and sidewall geometries respectively. This suggested that the excess temperature, $\mathrm{dT}_{\mathrm{p}}$ in the corner and sidewall geometries would be respectively 2.5 times and 1.6 times that deduced for the relatively open plume, centre fire case [3] as for a

given input $Q, \mathrm{dT}_{\mathrm{p}, \text { corner }} / \mathrm{dT}_{\mathrm{p}, \text { centre }}=\mathrm{m}_{\mathrm{p}, \text { centre }} / \mathrm{m}_{\mathrm{p}, \text { corner }}$ in the corner geometry and $\mathrm{dT}_{\mathrm{p}, \text { wall }} / \mathrm{dT}_{\mathrm{p}, \text { centre }}=\mathrm{m}_{\mathrm{p}, \text { centre }} / \mathrm{m}_{\mathrm{p}, \text { wall }}$ in the sidewall case, respectively. They further argued that the reduction in the entrainment rate in the fire plume region will result in a reduced hot gas layer depth within the enclosure and thus causing entrainment to occur over a greater height in the room. This would result in an excess temperature rise in the plume less than that deduced from the Mirror model argument. They proceeded to calculate doorway and plume mass rates including the expected layer height, $\mathrm{z}$ for energy release rates in the range of 50 to $1000 \mathrm{~kW}$ using a quasi steady state mass balance approach. They then deduced from the ratios of the calculated mass fluxes for the centre fires to the 
corner and side fires that the actual EFs were in the region of 1.7 and 1.3 for the corner and wall geometries respectively and thus identical to the factor increases required to identify the excess temperatures for these geometries as suggested by plume theory. As indicated above, these modifications have only been tested against a limited range of experimental data for a stepped output of $40 \mathrm{~kW}, 80 \mathrm{~kW}$ and $160 \mathrm{~kW}$ from a controlled propane diffusion burner placed in a PLA lined enclosure [3]. As such, an interrogation of the MQH correlations and suggested modifications for corner and sidewall geometries is prudent. The following sections summarise the initial results and analysis of an experimental study of near corner and centre fires as described in the experimental section.

\section{RESULTS, OBSERVATIONS AND ANALYSIS}

The two dimensionless variables, $\left(\mathrm{Q} 0^{*}\right)^{2 / 3}\left(\mathrm{QL}^{*}\right)^{-1 / 3}$, eqn. 2 were correlated to the well mixed upper gas layer temperature located at $100 \mathrm{~mm}$ below the ceiling, fig. 2 in the large scale test and at $25 \mathrm{~mm}$ below the ceiling in the $1 / 3$ scale test from which one corner test is included in the data presented. In expression 2, the ambient temperature was generally in the region of $290 \mathrm{~K}$ and $h_{k}$ was computed as described above. The physical material property data were obtained from literature[1,4]. In general, the mid-ceiling thermocouple temperature measurement was taken for convenience, but where this was absent or had failed, the averaged ceiling gas temperatures at the four quadrants, fig.1 was used instead. During the course of the fires, the integrity of the double glazing units were retained except for the latter part of the tests for the $1.0 \mathrm{~m}$ square trays. In the case of the single glazing tests, although extensive cracks formed in the glass, glass fallout was considerably delayed for the smaller tray sizes [6]. However the data was only taken for periods preceding catastrophic glazing failure, generally up to the peak energy release period. Figures 3-5 below show the variation of the measured ceiling gas layer temperature. In general, a power law expression of the form, $\mathrm{dT}=\mathrm{f}\left(\mathrm{Q}^{2 / 3}\right)$ could be used to describe the variation.

The results for the correlation of the data utilizing eqn. 2 in the case of the corner fire tests which include a $0.55 \mathrm{~m}$ tray placed at $50 \mathrm{~mm}$ from the room corner and a $1 / 3$ scale enclosure where the $0.2 \mathrm{~m}$ square fuel tray was placed $\sim 15 \mathrm{~mm}$ from the room corner is also shown, fig.6. The latter tests formed part of a study conducted on combustible lining fires [5,7] for which the applicability of the $\mathrm{MQH}$ correlation will be reported in a future paper. In fig. 6 , all the single glazed tests of tray sizes $0.5 \mathrm{~m}$ to $0.8 \mathrm{~m}$ were placed $\sim 15 \mathrm{~mm}$ from the room corner with the doorway at half width whereas the other tests referred to above were conducted at full door width. A value of $\mathrm{C}_{\mathrm{T}}$ of $856 \mathrm{~K}$ was found as indicated by the correlation equation shown, fig. 6 . Figure 7 shows the correlation for the centre geometry fires which includes data for tray sizes up to $1.0 \mathrm{~m}$ and ceiling gas temperatures in excess of $800^{\circ} \mathrm{C}$. Inclusion of these large fuel tray data where the intermittent flame tips impinge on the ceiling at energy release rates in excess of $400 \mathrm{~kW}$ did little to change the slope $\mathrm{C}_{\mathrm{T}}$ for the data shown. The value of $\mathrm{C}_{\mathrm{T}}$ obtained in this instance was $686 \mathrm{~K}$ as indicated from the correlation, fig. 7 with all the tests conducted with the doorway at half width. 
Fig. 3 Corner test, double glazing test with $0.55 \mathrm{~m}$ tray, full doorwidth, averaged ceiling gas temperature at the ceiling mid point vs total heat release rate

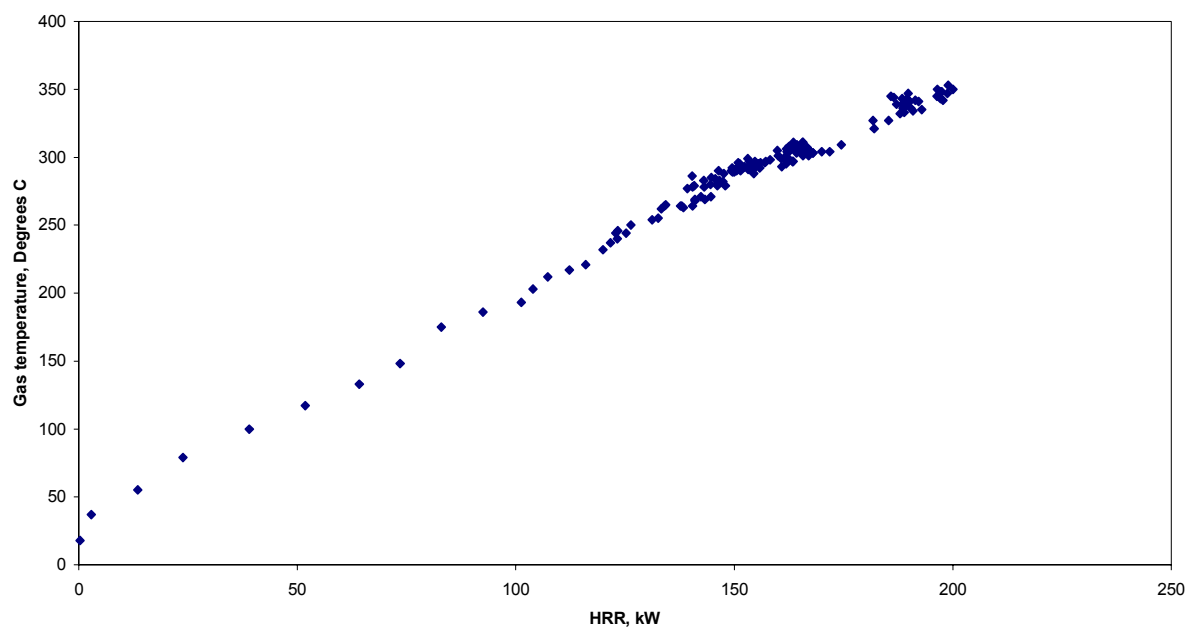

Fig. 4 Centre fire, single glazing SG25, $0.9 \mathrm{~m}$ tray, half doorway width, averaged ceiling gas temperature at $100 \mathrm{~mm}$ below the ceiling vs total heat release rate

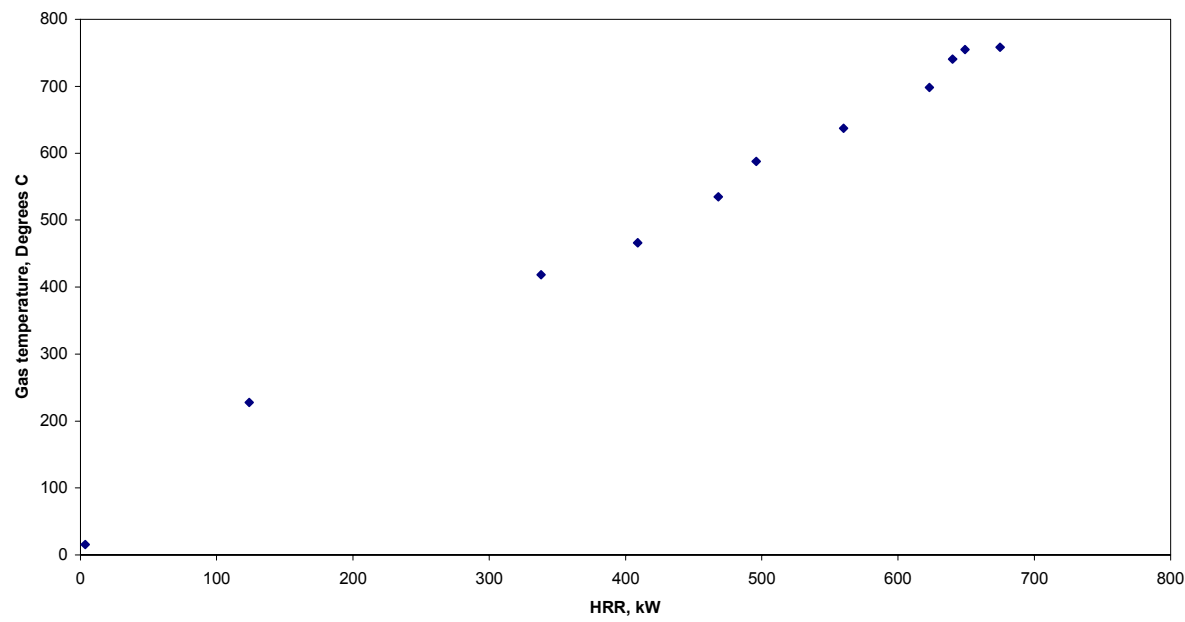


Fig. 5 Corner fire SG31, $0.8 \mathrm{~m}$ tray, half doorway width, averaged ceiling gas temperature at $100 \mathrm{~mm}$ below the ceiling vs total heat release rate

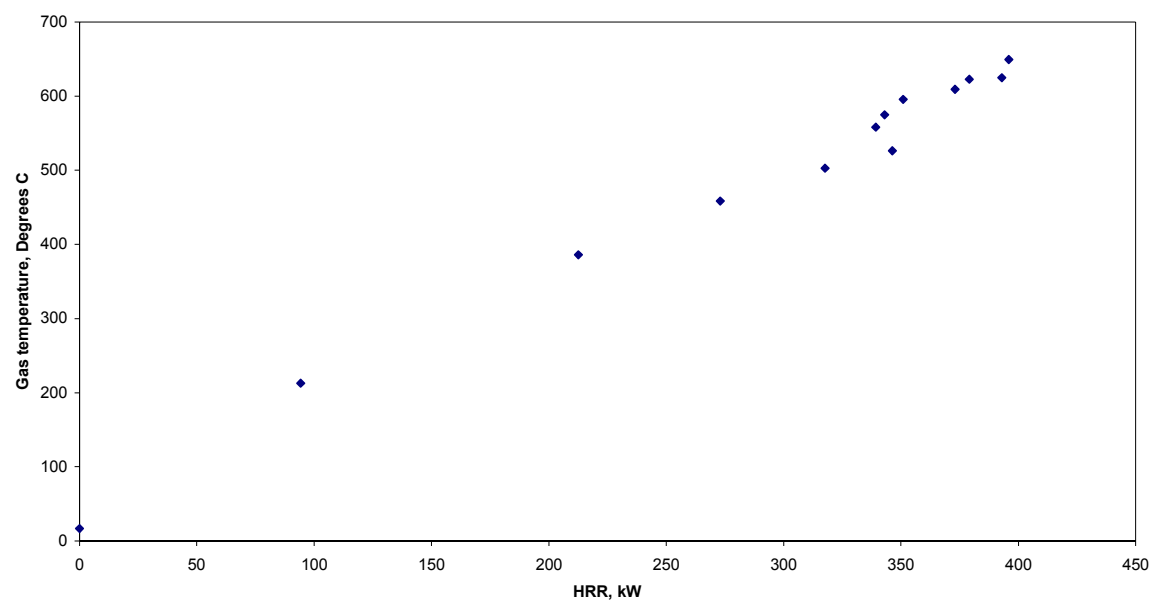

Fig. 6 Corner tests, correlation of temperature near ceiling with two dimensionless variables, single glazing tests with half doorway width and double glazing tests with fully opened doorway

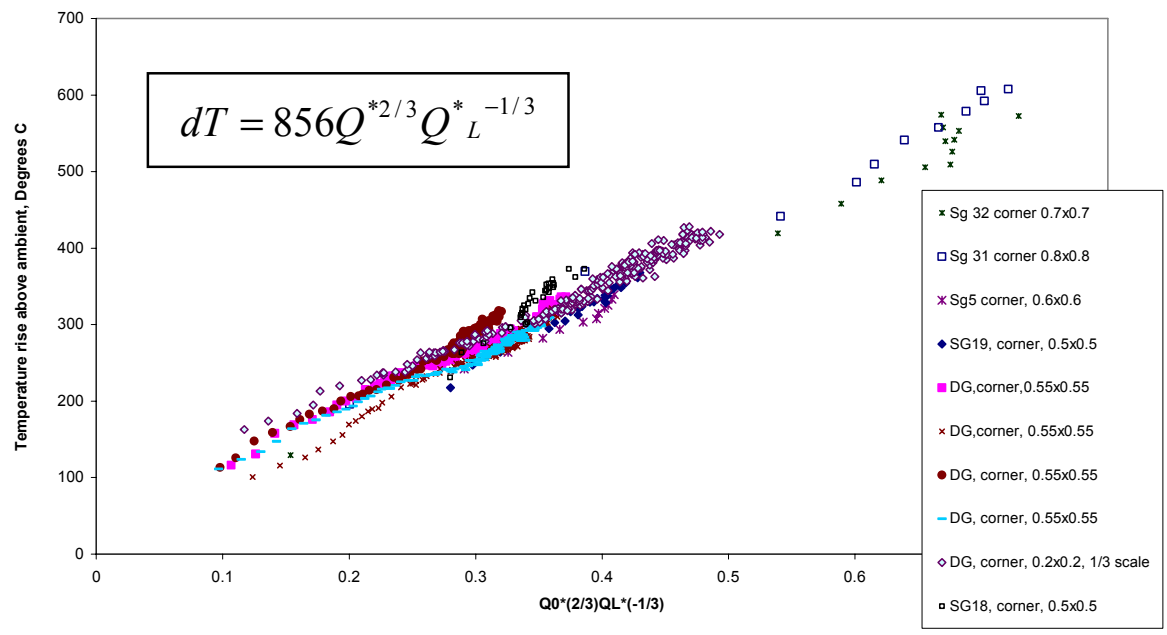


Fig. 7 Centre tests, correlation of temperature near ceiling with two dimensionless variables, single and double glazing tests with half doorway width

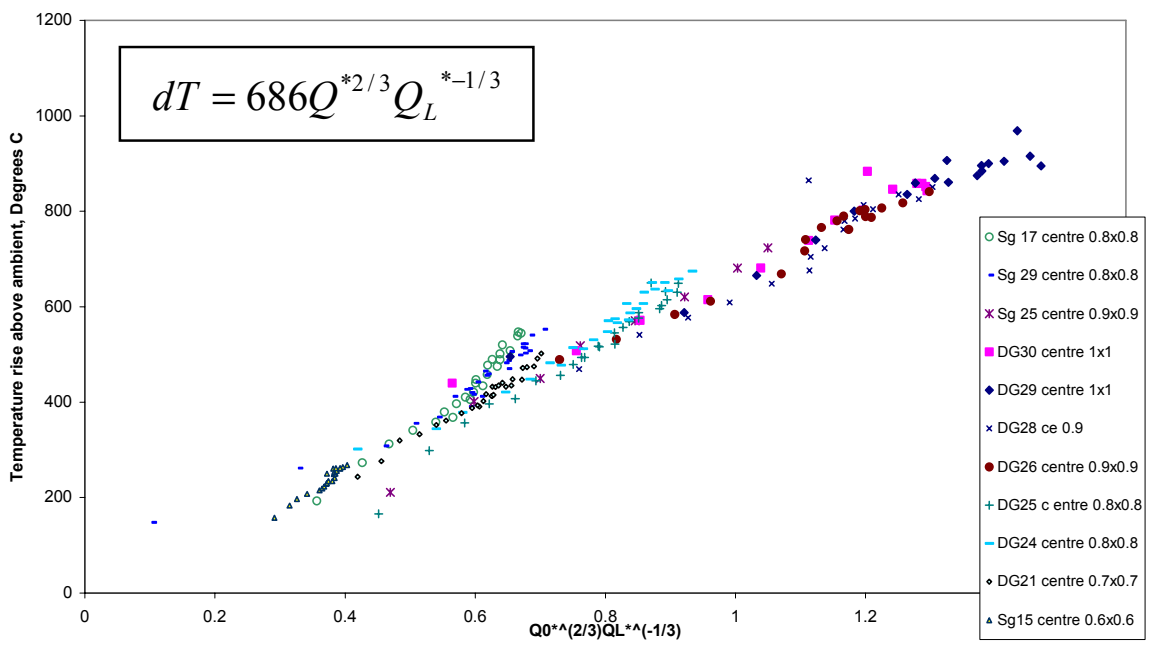

\section{DISCUSSION}

The results of the reported study using a liquid pool fire source to interrogate the original $\mathrm{MQH}$ correlation for centre fire [1] and modification for near corner fire geometries [3] suggest that that the two key dimensionless groups appearing in eqn. 2 adequetely correlate the well mixed ceiling gas temperatures measured near the ceiling. The results of the study also lends support to the MW modifications suggested for corner walls based on arguments of reduced air entrainment into the hot layer tempered by increased interface layer height [3]. In this instance, they obtained a value of $\mathrm{C}_{\mathrm{T}}$ of $804 \mathrm{~K}\left(@ \mathrm{~T}_{\mathrm{o}}\right.$ of $290 \mathrm{~K}$ ) for the corner geometry fire where the burner was abutted to the PLA lined wall surfaces. Their $\mathrm{C}_{\mathrm{T}}$ value is close to the value of $856 \mathrm{~K}$ obtained in this study for the near corner fires where the burners were located at $\sim 15 \mathrm{~mm}$ from the from the ceramic fiberboard lined walls except for one test at a $50 \mathrm{~mm}$ displacement.

In the case of the room centre fire data, the UUJ study suggests a value of 686 in comparison to $473 \mathrm{~K}$ (@ $\mathrm{T}_{\mathrm{o}}$ of $290 \mathrm{~K}$ ) obtained by MQH [1,3]. It is noted that most of the quality centre geometry data available were limited to the larger tray sizes, fig.7. These data therefore included ceiling gas temperatures up to $\sim 800^{\circ} \mathrm{C}$ and energy release rates were close to $600 \mathrm{~kW}$ in the case of the $0.9 \mathrm{~m}$ fuel tray whereas with the other fuel trays, the peak energy release rates were in the region of $400 \mathrm{~kW}(0.8 \mathrm{~m}$ tray). In the original $\mathrm{MQH}$ [1] work in which polymeric and cellulose cribs including gaseous fuels were utilised, an upper limit layer temperature of $600^{\circ} \mathrm{C}$ was found to hold in correlating both eqn. 1 and eqn.2. This was attributed to the possibility of flame impingement occurring in the upper gas layer and thus compromising the definition of a unique layer temperature. However, at the positions of gas temperature measurements at the ceiling, the average gas layer temperature followed the trend of fig. 2 even in the case of these larger tray sizes Excluding the larger tray sizes and examination of the admittedly poorer quality 
0.6diameter tray test data for the centre fires only succeeded in reducing $\mathrm{C}_{\mathrm{T}}$ to $628 \mathrm{~K}$. Further examination of the HRR data indicated that the peak $Q^{*}$ values for the tests considered were in the range of 0.5-0.8 with $\mathrm{Q}^{*}$ defined as $\dot{Q} / \rho_{o} C_{p} T_{o} g^{1 / 2} D^{5 / 2}$. In this range of $\mathrm{Q}^{*}$, the criteria for satisfying far field plume properties appear to hold from comparisons to data presented by Hasemi and Tokunaga [8] except for the case of energy release rates exceeding $600 \mathrm{~kW}$ in the later part of the $0.9 \mathrm{~m}$ fuel tray test where $\mathrm{Q}^{*}$ was noted to approach 0.8 . In the case of the tray sizes of $0.8 \mathrm{~m}$ or larger which at HRRs exceeding $500 \mathrm{~kW}$ would cause flame heights to approach the ceiling and thus $\mathrm{dT}_{\mathrm{p}}$ would be expected to rise faster than that suggested by eqn.1. The much increased upper gas layer temperatures and increasing heat feedback to the fuel surface from the hot gas layer with time would also be assisted by the lower interface height, $z_{n}$ associated with these larger liquid pool fires included in the centre geometry tests. The above suggests the possible explanations for the higher $\mathrm{C}_{\mathrm{T}}$ value noted in the present studies for the centre geometry fires compared to that reported in $[1,3]$.

The $\mathrm{C}_{\mathrm{T}}$ values were further examined by calculating the critical energy release rate $\mathrm{Q}_{\mathrm{cr}}$ $(\mathrm{kW})$ at a specific temperature rise, in this case, $620^{\circ} \mathrm{C}$ as deduced from the data and the ratio of $\mathrm{Q}_{\mathrm{cr} \text {, centre }} / \mathrm{Q}_{\mathrm{cr}, \text { corner }}$ was then calculated. The ratio obtained at 1.394 is almost identical to that deduced from a study due to B.T.Lee (1.397) as discussed in [4]. The influence of the maximum separation distance of the fuel source from the adjacent walls at $50 \mathrm{~mm}$ as used in the current study does not appear to be sufficiently large to show any difference in the corner geometry data correlation, fig.6. In this instance however, a comparison of the observed flame height to flame height correlations noted in [8] suggested that in the case of the $0.55 \mathrm{~mm}$ fuel tray placed at $50 \mathrm{~mm}$ from the room corner, the calculated continuous flame height at $0.7 \mathrm{~m}$ using the unconfined flame height correlation was closer to the observed values of $0.7-0.8 \mathrm{~m}$. In contrast, at the $15 \mathrm{~mm}$ spacing from the walls, the observed flame heights were closer to those calculated from the corner geometry continuous flame height correlations. In order therefore to delineate the precise dependence of $\mathrm{C}_{\mathrm{T}}$ on key factors, the pattern and magnitude of air flow into the fire plume and its associated gas plume and variations with $Q^{*}, z / D[9]$, the fuel source to adjacent walls separation distance(s) and other factors such as surface roughness, local heat loss through the walls[8], fuel tray geometry and entrainment height $z_{\mathrm{n}}$ must be considered[3,5]. It is clear that a systematic study is necessary to isolate the factors involved in order to further refine and extend the generality of highly promising and computationally economic MQH type correlations. Further analysis of the extent of the applicability of the modified MQH correlation to the case of corner geometry which included combustible linings will be addressed in future publications.

\section{SUMMARY}

An experimental study of Industial Methylated Spirits pool fires using square trays of sizes ranging from $0.2 \mathrm{~m}(1 / 3$ scale test enclosure with fuel elevated $100 \mathrm{~mm}$ from the floor) and $0.5-0.9 \mathrm{~m}$ (ISO scaled enclosure with fuel elevated $400 \mathrm{~mm}$ from the floor) has been conducted for the case of centre and near corner fire geometries. The measured energy release rates and well mixed ceiling gas temperature data at the specified location(s) have been correlated to two dimensionless groups as in eqn.2, originally 
derived by $\mathrm{MQH}$ [1] for the case of discrete centre fires. The following points are summarised,

(1)The correlations of the data produced indicate that the above mentioned dimensionless groups adequetely describe the variation of well mixed ceiling layer gas temperatures as indicated in figs. $6 \& 7$ and using the methodology suggested in the theory section.

(2)The values of the slopes $C_{T}$, derived from the correlations, figs. $6 \& 7$ in the case of discrete corner and centre liquid pool fire geometries were $856 \mathrm{~K}$ and $686 \mathrm{~K}$ respectively

(3)The $C_{T}$ value for the corner configuration is in accord with the modifications suggested by MW [3].

(4)The $\mathrm{C}_{\mathrm{T}}$ value for the centre configuration in this study is closer to the upper limit of the data range noted from the original $\mathrm{MQH}$ study [1]. This may have arisen from the size and severity of the quality centre geometry fire data available which was mainly limited to larger tray sizes tested at half doorway width where the flame height approached the ceiling with time.

(5)The critical energy release rates deduced from eqn2. using the $C_{T}$ values obtained indicate that the results are realistic and the calculated ratio of the critical energy release rate for the centre geometry to that in the corner fire geometry was found to be identical to that reported in a separate study as discussed in [4].

The precise dependence of $\mathrm{C}_{\mathrm{T}}$ for varying fire geometries would need to consider the pattern and magnitude of air flow into the fire plume and its associated gas plume which will be influenced by the fuel source to adjacent walls separation distance(s). Other factors to be considered are variations with $\mathrm{Q}^{*}, \mathrm{z} / \mathrm{D}[9]$, including factors such as surface roughness, local heat loss through the walls [8], fuel tray geometry and entrainment height $z_{n}[3,5]$.

\section{ACKNOWLEDGEMENTS}

The authors acknowledge financial support for parts of this study from EPSRC grants $\mathrm{GR} / \mathrm{K} 59828$ and GR/K87845 and to the University of Ulster for supporting a visit to FireSERT of Prof. J.G. Quintiere. The authors also acknowledge the able assistance of IAESTA student Ms. Minna Koppi from Finland.

\section{REFERENCES}

1. McCaffrey,B.J., Quintiere, J.G., and Harkleroad, M.F., "Estimating Room Temperatures and the Likelihood of Flashover Using Fire Test Data Correlations," Fire Technology 17, 98- 11 (1981).

2. Peacock, R. D., Reneke, P.A., Bukowski, R.W., and Babrauskas, V., "Defining Flashover for Fire Hazard Calculations," Fire Safety Journal 32:331-345 (1999).

3. Mowrer, F.W. and Williamson, R.B., Estimating Room Temperatures from Fires along Walls and in Corners, Fire Technology, 1987, Vol.23, pp.244-265. 
4. Drysdale.D., An Introduction to Fire Dynamics $\left(2^{\text {nd }}\right.$ ed), John Wiley and Sons, Chichester, 1998, p.310.

5. Zhang, J., Shields, T.J., Silcock, G.W.H. and Azhakesan, M.A., "Performance of Plywood Linings and its Influence on Enclosure Fire," Fire and Materials, accepted for publication, 2002.

6. Hassani, S.K.S., Shields, T. J. and Silcock, G.W.H., "An Experimental Investigation into the Behaviour of Glazing in Enclosure Fire," in The Behaviour of Glass and other Materials Exposed to Fire, DeCicco, P.R.(ed.), Applied Fire Science in Transition Series, 11:3-22 (2000).

7. Shields, T.J., Silcock, G.W.H. and O'Conner, D.J. "Performance Simulation of Enclosure Linings Subjected to Realistic (typical) Regimes of Fire Exposure Conditions”, EPSRC Research Grant Report, GR/K87845,UK, 2000.

8. Hasemi, Y. and Tokunaga, T., Some Experimental Aspects of Turbulent Diffusion Flames and Buoyant Plumes from Fire Sources Against a Wall and in a Corner of Walls, Combustion Science and Technology, 40: 1-17 (1984).

9. Poreh, M. and Garrad, G., A Study of Wall and Corner Fire Plumes, Fire Safety Journal, 34: 81-98 (2000). 